doi:10.17659/01.2018.0033

Journal of Case Reports 2018;8(2):125-128

\title{
Aneurysmal Bone Cyst of Third Metatarsal in a Young Child
}

\author{
SK Shriram, AN Vivek, AB Govindaraj \\ Department of Orthopaedics, Fortis Malar Hospital, Gandhinagar, Adyar, Chennai- 600020, India.
}

\section{Corresponding Author: \\ Dr. SK Shriram}

Email: skshriram@gmail.com

This is an Open Access article distributed under the terms of the Creative Commons Attribution License (creativecommons.org/ licenses/by/3.0).

Received : November 18, 2017

Accepted : April 9, 2018

Published : May 15, 2018

\begin{abstract}
Background: Aneurysmal bone cyst (ABC) is a relatively rare benign, locally expansile, hemorrhagic lesion. It accounts for $1 \%$ of all bone tumors. It predominantly involves long bones, pelvis and spine. $\mathrm{ABC}$ of metatarsal is relatively rare and very few case reports have been published in literature till date. Case Report: This study reports ABC of $3^{\text {rd }}$ metatarsal in a 5 year old boy, who presented with on and off pain and swelling in his right forefoot. X-ray revealed a lytic, expansile lesion with thin cortical rim in body of $3^{\text {rd }}$ metatarsal. Curettage of the lesion through a bony window was done and filled up with synthetic bone graft. Histopathology of the curetted sample revealed the diagnosis as ABC. Conclusion: The present study aims to describe a case of $\mathrm{ABC}$ of metatarsal, a condition that poses a diagnostic challenge and to establish the significance of radiological and histological examination for diagnostic accuracy.
\end{abstract}

Keywords: Aneurysmal Bone Cyst, Bone Neoplasms, Curettage, Metatarsal Bones, Pain.

\section{Introduction}

Aneurysmal bone cyst $(\mathrm{ABC})$ is a relatively rare benign, locally expansile, hemorrhagic lesion predominantly in first and second decade of life (95\%) [1-3]. It occurs as primary lesion in $80 \%$ cases and secondary to other bony lesion in $20 \%$ [4]. Overall it accounts to $1 \%$ of bony tumors $[5,6]$. It can involve any bone, but mostly metaphysis of the long bones are affected (65\%), pelvis (15\%) and spine (15\%) [7]. The differential diagnosis associated with this lesion include unicameral or simple bone cyst, giant cell tumor (GCT), Brown's tumor secondary to hyperparathyroidism, giant cell reparative granuloma (GCRG) [8-10]. Treatment options for $\mathrm{ABC}$ are curettage or resection and bone grafting with or without adjuvant like phenol, liquid nitrogen $[11,12]$. The present reports a case of $\mathrm{ABC}$ localized to metatarsal, a relatively rare presentation of which only few cases have been reported in literature till date.

\section{Case Report}

A 5 year old boy was brought by his parents with complaints of on and off pain in his right foot. They noted swelling in his right foot whenever he had pain. It aggravated on activity and relieved after a period of rest. These symptoms have been for the past five months. Initially they met a doctor who diagnosed it as fracture and advised splinting, but they pain persisted with waxing and waning after the splint was removed. He had no other constitutional symptoms associated.

Physical examination revealed a tender, densely indurated, immobile swelling measuring 5 $\mathrm{cm}$ in diameter localised to right forefoot. Standard foot $\mathrm{x}$-ray revealed a well demarcated, expansile lesion with thin cortical margin localised to $3^{\text {rd }}$ metatarsal [Fig.1]. The boy underwent surgery where a window was made through the lateral cortex and the lesion was thoroughly curated and sent for histopathology. The void was filled with synthetic bone graft, calcium sulfate (Stimulan). 
Intra-operative finding of the lesion appeared bluish red, bulbous with thinned out cortical shell measuring $5 \times 4 \times 2 \mathrm{~cm}$. Microscopic appearance showed large amounts of dilatation and congestion of the associated small blood vessels, osteoblast proliferation, fibrous connective tissue and multinucleated giant cell proliferation, with reactive hyperplasia and trabecular bone tissue. Final diagnosis of $\mathrm{ABC}$ was made after collective clinical information. The treatment was successful as no further intervention was required in one year follow-up and the patient remains healthy at present [Fig.2-4]. But due to 20\% recurrence in open physis, the child will be followed closely till skeletal maturity.

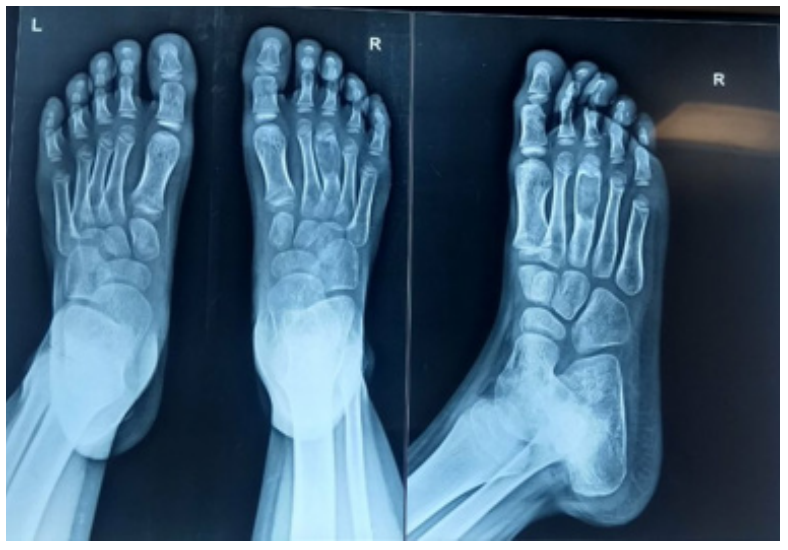

Fig.1: Pre-operative $X$-ray view.

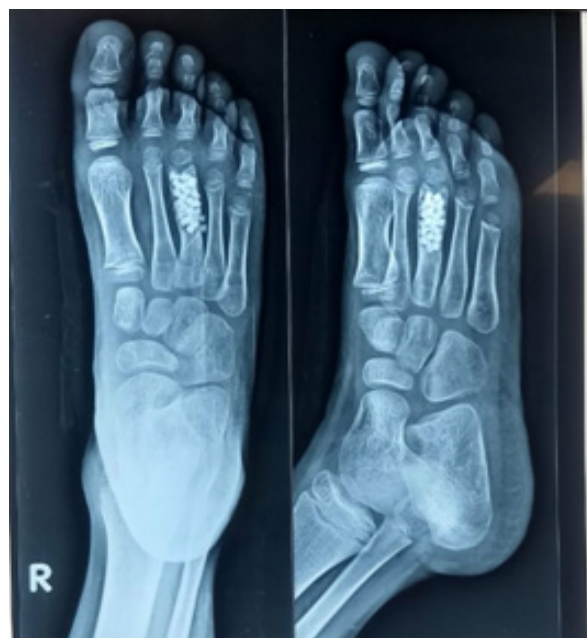

Fig.2: Immediate post-operative view.

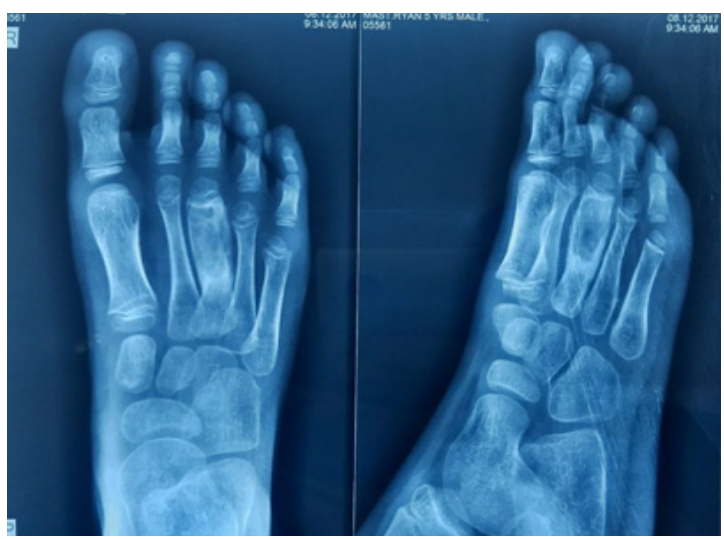

Fig.3: One month post-operative view.

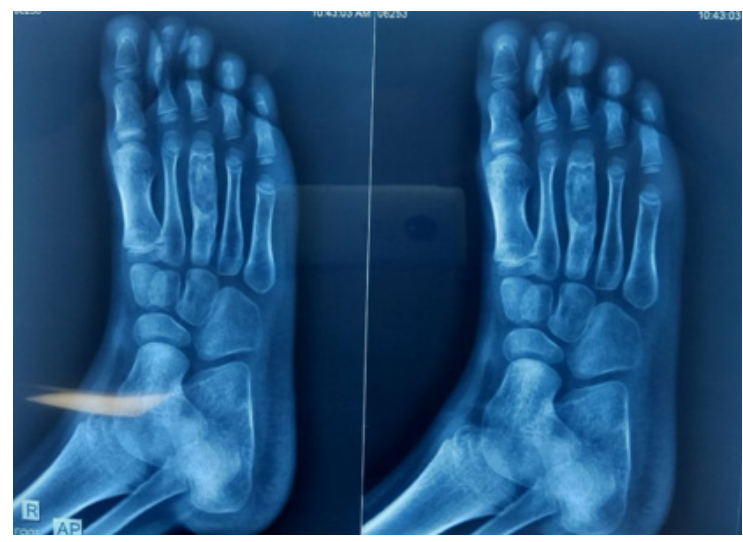

Fig.4: Three months post-operative view.

\section{Discussion}

ABCs account for $1 \%$ of all primary bone lesions that are sent for biopsy [11]. Though the precise pathogenesis of $\mathrm{ABC}$ is unclear, the most widely accepted hypothesis of $\mathrm{ABC}$ involves local circulatory disturbance, which results in an increase in venous pressure and the development of enlarged and dilated vascular components within the affected bone [2]. The differentiation of $\mathrm{ABC}$ and other giant cell-containing tumors of the bone, such as GCT, GCRG and Brown tumor, is crucial [11]. GCT is composed of mononuclear and osteoclast-like multinucleated giant cells, which have the potential to be locally aggressive $[14,15]$. In GCT, the tumor is an epiphyseal lesion always eccentric and exhibits lytic expansion [16]. GCRG is a rare, benign, intra-osseous reactive lesion, 
characterized pathologically by a predominance of giant and mononuclear cells in areas of hemorrhage [17]. Brown tumors have been reported to occur in $1-2 \%$ of patients with chronic renal deficiency and to have a considerably more lobulated architectural growth pattern; but hyperparathyroidism can be ruled out as a differential diagnosis on the basis of serum calcium, parathyroid and phosphorus hormone levels $[18,19]$. ABC, on the other hand, is known to be histologically composed of bloodfilled cystic spaces separated by fibrous septae [20].

Though X-ray finding is classical, computed tomography, MRI and bone scans may be helpful in the diagnosis of $A B C$, since T2-weighted MRI could detect a deformity in the involved metatarsal bone as a segmented, expansile, multi-septated lesion with a large quantity of fluid present [21] and bone scan shows donut sign. Both curettage and en-bloc surgical removal is considered the optimal treatment option for $\mathrm{ABC}$. The lesion is removed by intra-lesional curettage through a wide cortical window, and allograft or synthetic bone grafting may be used to fill up of bone defects [22]. Embolotherapy has also been successfully used for the treatment of ABCs [23]. However, patients must be informed that $\mathrm{ABC}$ has a high recurrence rate [24], so that any recurrence or malignant transformation can be detected as early as possible.

In summary, $\mathrm{ABC}$ is a destructive, hemorrhagic and tumor-like lesion occurring predominantly in teenaged patients. Radiographs and MRI scans can often confirm the diagnosis of $\mathrm{ABC}$; however, accurate histological evaluation is imperative for diagnosis. Curettage with bone grafting [11], embolotherapy and replacement of bone defects with a autograft are considered safe procedures with minimal recurrence risk.

\section{Conclusion}

The present study described a rare case of a ABC in the metatarsal and highlighted the importance of radiological and histological examinations for the accuracy of such diagnosis
Contributors: SKS: manuscript writing, patient management; ANV: manuscript editing, patient management; ABG: critical inputs into the manuscript. SKS will act as guarantor. All authors approved the final version of this manuscript.

Funding: None; Competing interests: None stated.

\section{References}

1. Jaffe HL, Lichtenstein L. Solitary unicameral bone cyst with emphasis on the roentgen picture, the pathologic appearance and the pathogenesis. Arch Surg. 1942;44:1004-1025.

2. Cottalorda J, Bourelle S. Modern concepts of primary aneurismal bone cyst. Arch Orthop Trauma Surg. 2007; 127:105-114.

3. Singh DK, Singh N, Pant MC. Aneurysmal bone cyst: An unusual presentation of back pain. Asian J Neurosurg. 2014;9:105-107.

4. Lichtenstein L. Aneurysmal bone cyst: A pathological entity commonly mistaken for giant cell tumor and occasionally for hemangioma and osteogenic sarcoma. Cancer. 1950;3:279-289.

5. Hakim DN, Pelly T, Kulendran M, Caris JA. Benign tumours of the bone: A review. J Bone Oncol. 2015;4:3741.

6. Bonakdarpour A, Levy WM, Aegerter E. Primary and secondary aneurysmal bone cysts: A radiological study of 75 cases. Radiology. 1978;126:75-83.

7. Campanacci M, Capanna R, Picci P. Unicameral and aneurysmal bone cysts. Clin Orthop Relat Res. 1986;204:25-36.

8. Barnhart MD. Malignant transformation of an aneurysmal bone cyst in a dog. Vet Surg. 2002;31:519524.

9. Hsu CS, Hentz VR, Yao J. Tumours of the hand. Lancet Oncol. 2007;8:157-166.

10. Saito T, Oda Y, Kawaguchi K, Tanaka K, Matsuda S, Sakamoto A, Iwamoto Y, Tsuneyoshi M. Five-year evolution of a telangiectatic osteosarcoma initially managed as an aneurysmal bone cyst. Skeletal Radiol. 2005;34:290-294.

11. Freiberg A, Loder R, Heidelberger $\mathrm{K}$, Hensinger RN. Aneurysmal bone cysts in young children. J Pediatr Orthop. 1994;14:86-91.

12. Ozaki T, Hillmann A, Lindner N, Winkelmann W. Aneurysmal bone cysts in children. J Cancer Res Clin Oncol. 1996;122:767-769.

13. Ozaki T, Hillmann A, Lindner N, Winkelmann W. Aneurysmal bone cysts in children. J Cancer Res Clin Oncol. 1996;122:767-769.

14. Foo LF, Raby N. Tumours and tumour-like lesions in the foot and ankle. Clin Radiol. 2005;60:308-333.

15. Ratner V, Dorfman HD. Giant-cell reparative granuloma of the hand and foot bones. Clin Orthop Relat Res. 1990;260:251-258. 
16. Futamura N, Urakawa H, Tsukushi S, Arai E, Kozawa E, Ishiguro N, et al. Giant cell tumor of bone arising in long bones possibly originates from the metaphyseal region. Oncol Lett. 2016;11:2629-2634.

17. Cook DL, Rosenthal DC, Shikoff MD. Giant cell reparative granuloma of the middle phalanx of the foot: A review and case report. J Foot Ankle Surg. 2008;47:589593.

18. Hanna BG, Donthineni R, Majid K, Parekh S, Shin JS, Lackman RD. Leg mass in a 61-year-old man. Clin Orthop Relat Res. 2003;406:298-307.

19. Brindley GW, Greene JF, Jr, Frankel LS. Case reports: Malignant transformation of aneurysmal bone cysts. Clin Orthop Rel Res. 2005;438:282-287.

20. Gibbs PC Jr, Hefele MC, Peabody TD, Montag AG, Aithal V, Simon MA. Aneurysmal bone cyst of the extremities. Factors related to local recurrence after curettage with a high-speed burr. J Bone Joint Surg Am. 1999;81:1671-1678.
21. Iltar S, Alemdaroğlu KB, Karalezli N, Irgit K, Caydere M, Aydoğan NH. A case of an aneurysmal bone cyst of a metatarsal: Review of the differential diagnosis and treatment options. J Foot Ankle Surg. 2009;48:74-79.

22. Boubbou M, Atarraf K, Chater L, Afifi A, Tizniti S. Aneurysmal bone cyst primary-about eight pediatric cases: Radiological aspects and review of the literature. Pan Afr Med J. 2013;15:111.

23. Rastogi S, Varshney MK, Trikha V, Khan SA, Choudhury B, Safaya R. Treatment of aneurysmal bone cysts with percutaneous sclerotherapy using polidocanol. A review of 72 cases with long-term follow-up. J Bone Joint Surg Br. 2006;88:1212-1216.

24. Cugati G, Pande A, Jain PK, Symss NP, Ramamurthi $\mathrm{R}$, Vasudevan CM. Aneurysmal bone cyst of the lumbar spine. Asian J Neurosurg. 2015;10:216-218.

25. deKleuver M, van der Heul RO, Veraart BE. Aneurysmal bone cyst of the spine: 31 cases and the importance of the surgical approach. J Pediatr Orthop B. 1998;7:286-292. 